\title{
Screen time and developmental health: results from an early childhood study in Canada
}

\author{
Salima Kerai', Alisa Almas, Martin Guhn, Barry Forer and Eva Oberle
}

\begin{abstract}
Background: Research has shown that longer hours of screen time are negatively associated with children's healthy development. Whereas most research has focused on school-age children, less is known about this association in early childhood. To fill this gap, we examined the association between screen time and developmental health in preschool-aged children.

Methods: This study draws from a data linkage on children ( $N=2983$; Mean age $=5.2, S D=0.3$ years, 51\% male) in British Columbia (BC), Canada, who entered Kindergarten in public elementary schools in 2019. Parent reports on children's screen time, health behaviors, demographics, and family income collected upon kindergarten entry (09/2019), were linked to teacher reports on children's developmental health, collected halfway through the school year (02/2020). Screen time was assessed with the Childhood Experiences Questionnaire. Developmental vulnerability versus developmental health in five domains (physical, social, emotional, language and cognition, and communication skills) was measured with the Early Development Instrument.

Results: Logistic regression analyses using generalized estimating equation showed that children with more than one hour of daily screen time were more likely to be vulnerable in all five developmental health domains: physical health and wellbeing (odds ratio $[O R]=1.41 ; 95 \%$ confidence interval $[C I], 0.99-2.0 ; p=0.058$ ), social competence $(O R=1.60 ; 95 \% \mathrm{Cl}, 1.16-2.2 ; p=0.004)$, emotional maturity $(O R=1.29 ; 95 \% \mathrm{Cl}, 0.96-1.73 ; p=0.097)$, language and cognitive development $(O R=1.81 ; 95 \% \mathrm{Cl}, 1.19-2.74 ; p=0.006)$ and communication skills $(O R=1.60 ; 95 \% \mathrm{Cl}, 1.1-2.34$; $p=0.015$ ) compared to children reporting up to one hour of screen time/day. An interaction effect between income and screen time on developmental health outcomes was non-significant. Results were adjusted for child demographics, family income, and other health behaviors.

Conclusions: Daily screen time that exceeds the recommended one-hour limit for young children, as suggested by the Canadian 24-h Movement Guidelines for Children and Youth (Tremblay et al. BMC Public Health. 17:874, 2017; Tremblay J Physical Activity Health. 17:92-5, 2020) is negatively associated with developmental health outcomes in early childhood. Screen-based activities should thus be limited for young children. Future research needs to examine the underlying mechanisms through which screen time is linked to developmental vulnerabilities.
\end{abstract}

Keywords: Screen time, Developmental health, Early childhood, Health behaviors, Family income, Canada

*Correspondence: skerai@mail.ubc.ca

School of Population and Public Health, the Human Early Learning Partnership, The University of British Columbia, 2206 East Mall, BC V6T 1 Z3 Vancouver, Canada

\section{Background}

In the past two decades, screen time (e.g., watching television, playing virtual games) has almost doubled among young children $[1,2]$. Screens have a ubiquitous presence in children's day-to-day lives, are easy to access, and serve as a frequent platform for activity and entertainment [3]. While screen use can be beneficial for children to 
some extent (e.g., participation in educational programs) [4], prolonged screen use in childhood has been linked to negative developmental health outcomes including obesity [5], behavior problems [6], emotion regulation problems [7], speech delays [8], lower executive functioning [9] and academic problems [10]. It has further been suggested that time spent in screen-based activities displaces free and active play in childhood to some extent, interferes with social interactions (e.g., with family and peers) and impacts sleep duration and quality $[9,11,12]$. Some research suggests that screen time may be particularly concerning for children from low income families. In a study with $N=803$ pre-school aged children, lower income was related to more time spent watching television; the association between watching television and lower cognition functioning and problem-solving skills was moderated by income and significantly stronger for children from low income families [13].

In response to the public health concerns resulting from increases in screen time, Canadian and international researchers, non-government organizations (e.g., ParticipACTION), and policy makers developed the 24-H Movement Guidelines for the Early Years in 2017, to encourage and promote optimal health behaviors in early childhood [14, 15]. The guidelines recommend that children under the age of five limit screen time to $1 \mathrm{~h}$ per day. Further, the guidelines recommend that children under the age of five be physically active for at least 180 min per day and get at least $10 \mathrm{~h}$ of sleep in a 24-h period. A recent study with a nationally representative sample of pre-school aged children in Canada found that while a majority of children met the recommendations specified by the 24-h guidelines for physical activity $(61.8 \%)$ and sleep duration (83.9\%), only a quarter of children met the recommended $1 \mathrm{~h}$ screen time limit per day [16].

The goal of this study was to examine whether meeting versus exceeding daily screen time recommendations in early childhood (i.e., $>1 \mathrm{~h}$ /day) was associated with developmental vulnerability in social, emotional, cognitive, and physical domains, taking into account other important health behaviors (i.e., physical activity, sleep) and children's demographic backgrounds (sex, family income, ethnicity, living in rural versus urban communities living).

This study addresses several gaps in research. Research to date has predominately examined screen time in older children [17-19] and less is known about the association between screen time and developmental health in early childhood. Further, few studies on screen time integrate other important health behaviors (e.g., physical activity, sleep) as well as contextual variables that are associated with children's developmental health (e.g., family income, ethnic background, rural versus urban living). Whereas a majority of research has examined screen time in relation to physical health, such as childhood obesity [5], there is a dearth of research that takes a whole-child approach and incorporates a broader range of developmental health indicators in early childhood (i.e., physical, social, emotional, and cognitive health, and communication skills).

The present study draws from a large database of parent-reported child health behaviors and demographics collected upon Kindergarten entry, linked to teacher reports on children's developmental health 6 months later. Based on previous research, we hypothesized that children who exceeded the daily recommended screen time limits were more likely to be vulnerable in social, emotional, physical and cognitive development, after adjusting for the effects of family income, child and family demographics, and children's sleep and physical activity levels. Given that some research has shown differences in screen time among preschool-aged children by family income [13], we also examined whether there were differences in children exceeding screen time recommendations based on family income, and whether the association between screen time and developmental health was moderated by family income.

\section{Methods}

\section{Participants}

This study followed the Strengthening the Reporting of Observational Studies in Epidemiology (STROBE) reporting guidelines [20]. Participants were $N=2983$ children in British Columbia (BC), Canada, who had participated in the Childhood Experiences Questionnaire (CHEQ; caregiver-report) Project and in the Early Development Instrument (EDI); teacher report) project in the 2019/20 school year. Primary caregivers' responses on the CHEQ, collected in September 2019 [21] were linked to teachers' responses on the EDI, collected in February 2020 [22]. The majority of the primary caregivers were parents: mothers $(N=2421,81.2 \%)$ and fathers $(N=$ 427, 14.3\%). The CHEQ measures child and family demographics and children's health behaviors at Kindergarten entry; the EDI measures children's developmental health midway through the Kindergarten year. Detailed information on sampling for school districts for the CHEQ has been provided elsewhere [23].

Children in the sample came from 144 schools within nine school districts in BC (there are a total of 60 school districts and 1038 public elementary schools in BC) [23]. The mean age of children was $5.2, S D=0.3$ years at the time of the CHEQ implementation and 5.6, $S D=0.3$ at the time of the EDI implementation. The average participation rate for the CHEQ across school districts was 57\%. The CHEQ-EDI linkage rate was $98.3 \%$. Individual 
child-level data on the CHEQ were linked to their EDI survey by Population Data BC via unique identifiers (i.e. Personal Education Numbers) [24]. Data were accessed via a secure server at Population Data BC [25].

\section{Measures}

Information on all explanatory variables (i.e., screen time, sleep, physical activity ethnicity, sex, annual household income) was obtained from the CHEQ. Screen time was the main exposure variable of interest. Sleep, physical activity, family ethnicity, child sex, family annual household income, and rural versus urban community were included as covariates based on their role as potential confounders in predicting developmental health [17, 26-29]. Information on outcome variables (i.e., physical health/wellbeing, social competence, emotional maturity, language and cognitive development, communication skills) was obtained from the EDI. Descriptive statistics for all variables can be found in Table 1 .

\section{Screen time}

Screen time was assessed by asking parents: "Think about the past 6 months, on average, how much time per day did your child use an electronic device like a tablet, smartphone, TV or computer (alone)?". Response options were $1=$ None; $2=<15 \mathrm{~min} ; 3=15 \mathrm{~min}$ to $1 \mathrm{~h} ; 4=1-2 \mathrm{~h}$; $5=>2 \mathrm{~h}$. Based on the 24-hour movement guidelines [14] for the early years, screen time was categorized into $0(\leq 1 \mathrm{~h})$ and $1(>1 \mathrm{~h})$.

\section{Physical activity}

Physical activity was assessed by asking parents "In the last 6 months, about how many times per week did your child take part in energetic physical activity while participating in organized activities (for example, swimming lessons or gymnastics lessons)?" Response options were $1=$ Never; $2=$ Once a week or less; $3=2-3$ times week; 4=4-5 times a week; $5=6-7$ times a week. For subsequent analyses, responses were grouped into $1=$ participant (participation at least once per week) and 0 = non-participant (never participated). Distinguishing between participants and nonparticipants is a commonly used indicator for preschool aged children's involvement in organized physical activity in absence of objective record of number of minutes spent in a day [30].

\section{Sleep}

Sleep was assessed by asking parents "How many hours does your child usually sleep in a 24-h period (Combining night time sleep and naps)?" In response parents indicated number of hours. Based on the 24-h movement guidelines [14], responses were grouped into 1, indicating
Table 1 Descriptive Statistics on Demographics and Health Behaviors Among Preschool-Aged Children in British Columbia, Canada

\begin{tabular}{|c|c|c|}
\hline & Variables & $\begin{array}{l}\text { Total sample } \\
N(\%)\end{array}$ \\
\hline \multicolumn{3}{|l|}{ Explanatory Variables on the CHEQ } \\
\hline \multirow[t]{3}{*}{ Screen time } & $>1 \mathrm{~h}$ & $1183(39.7 \%)$ \\
\hline & $\leq 1 \mathrm{~h}$ & $1734(58.1 \%)$ \\
\hline & Missing & $66(2.2 \%)$ \\
\hline \multirow[t]{2}{*}{ Sex } & Male & $1558(52.2 \%)$ \\
\hline & Female & $1425(47.8 \%)$ \\
\hline \multirow[t]{3}{*}{ Ethnicity } & European origins & $1602(53.7 \%)$ \\
\hline & Non-Euro. origins ${ }^{a}$ & $1048(35.1 \%)$ \\
\hline & Missing & $333(11.2 \%)$ \\
\hline \multirow[t]{3}{*}{ Annual family income } & $<\$ 75,000$ & $826(27.7 \%)$ \\
\hline & $\geq \$ 75,000$ & $1640(55.0 \%)$ \\
\hline & Missing & $517(17.3 \%)$ \\
\hline \multirow[t]{2}{*}{ Population Centre } & Urban & $1596(53.5 \%)$ \\
\hline & Small to medium & $1387(46.5 \%)$ \\
\hline \multirow[t]{3}{*}{ Physical activity } & Nonparticipant & $526(17.6 \%)$ \\
\hline & Participant & $2416(81.0 \%)$ \\
\hline & Missing & $41(1.4 \%)$ \\
\hline \multirow[t]{3}{*}{ Duration of sleep } & $<10 h$ & $303(10.2 \%)$ \\
\hline & $\geq 10 \mathrm{~h}$ & $2616(87.7 \%)$ \\
\hline & Missing & $64(2.1 \%)$ \\
\hline \multicolumn{3}{|l|}{ Dependent Variables on the EDI } \\
\hline \multirow[t]{3}{*}{ Physical health and wellbeing } & Not vulnerable & $2521(84.5 \%)$ \\
\hline & Vulnerable & $319(10.7 \%)$ \\
\hline & Missing & $143(4.8 \%)$ \\
\hline \multirow[t]{3}{*}{ Social competence } & Not vulnerable & $2460(82.5 \%)$ \\
\hline & Vulnerable & $377(12.6 \%)$ \\
\hline & Missing & $146(4.9 \%)$ \\
\hline \multirow[t]{3}{*}{ Emotional maturity } & Not vulnerable & $2408(80.7 \%)$ \\
\hline & Vulnerable & $427(14.3 \%)$ \\
\hline & Missing & $148(5.0 \%)$ \\
\hline \multirow{3}{*}{$\begin{array}{l}\text { Language and cognitive develop- } \\
\text { ment }\end{array}$} & Not vulnerable & $2580(86.5 \%)$ \\
\hline & Vulnerable & $244(8.2 \%)$ \\
\hline & Missing & $159(5.3 \%)$ \\
\hline \multirow[t]{3}{*}{ Communication skills } & Not vulnerable & $2544(85.3 \%)$ \\
\hline & Vulnerable & 295 (9.9\%) \\
\hline & Missing & $144(4.8 \%)$ \\
\hline
\end{tabular}

Note. $N=2983 .{ }^{a}$ Non- European origins include families with Indigenous, East Asian, South East Asian, South Asian, Latin America, Middle East, African background

optimal sleep duration (i.e., $\geq 10 \mathrm{~h}$ ) and 0 , indicating less sleep than recommended (i.e., $<10 \mathrm{~h}$ ).

\section{Demographics}

Families indicated their ethnicity by endorsing one or more of nine ethnic categories they were presented with. 
The category indicating European origins was checked by $53 \%$ of families. A binary ethnicity variable was therefore created for subsequent analyses: $0=$ European origins; 1 $=$ Non-European origins. Income was assessed by asking parents to indicate their best estimate of their family's overall household income in the previous year before taxes: $1=$ under $\$ 20,000 ; 2=\$ 20,000$ to $\$ 49,999 ; 3=$ $\$ 50,000$ to $\$ 74,999 ; 4=\$ 75,000$ to $\$ 99,999 ; 5=\$ 100,000$ to $\$ 149,999 ; 6=\$ 150,000$ to $\$ 199,999 ; 7=\$ 200,000$ or more. For further analyses, we created a binary variable indicating whether household income was less than $\$ 75,000$ versus $\$ 75,000$ or more. This cut-off was determined based on the 2019 living wages for families of two parent household in Metro Vancouver where both parents were full-time ( $\$ 19.50 /$ hour, resulting in approximately $\$ 75,000$ before taxes) [31]. Statistics Canada's criteria were used to categorize school districts into urban (i.e. population of 100,000 and more) and rural (small and medium population centers i.e., <100,000) [32].

\section{Developmental health}

Children's developmental health was assessed in five domains: physical health and wellbeing (13 items); social competence (26 items); emotional maturity ( 30 items); language and cognitive development (26 items); and communication skills (8 items). Responses on these domains were assessed on 2- or 3- point Likert scales (i.e., yes, no, don't know; very true, sometimes or somewhat true, never or not true, don't know). In alignment with previous research with the EDI [33], all responses on binary items were coded 0 or 10 and 3-point Likert-scale items were coded as 0,5 , and 10 . All items contained an additional response option, don't know (coded 99), which was not included in the statistical analyses. For every item, 10 designates the highest (i.e., most positive, most developmentally desirable) score. For every domain, the average score was calculated for each child, ranging from 0 to 10 . Subsequently, children's domain specific scores were converted into a dichotomous measure of vulnerability $(0=$ not vulnerable; $1=$ vulnerable). As in previous research with the EDI, vulnerability for a given developmental domain was indicated by a child's score being below a domain-specific cut-off score that marked the bottom 10th percentile in the normative distribution of kindergarten children, based on the first cycle of data collected in $\mathrm{BC}[29,34,35]$. The scoring procedure for the EDI was developed by the instrument's authors in collaboration with educators and knowledge users [29, 34, 35]. Previous research has supported the use of vulnerability scores in research with the EDI [36, 37]. The EDI's validity has been supported in previous research, and good interrater reliability has been established [38-40]. In the present study, the internal consistency was satisfactory for all domains (Cronbach's alphas $>0.86$ ), except for physical health (Cronbach's alpha $=0.45$ ). Regarding the interrelatedness of outcome domains, correlations were mostly small to moderate ranging from 0.32 (emotional maturity and language development) to 0.48 (language development and communication), except for a large correlation of 0.66 between social competence and emotional maturity.

\section{Statistical analyses}

Exploratory and bivariate analyses were conducted among all explanatory and dependent variables. To examine the differences in children exceeding screen time recommendations based on family income, Pearson's Chi-square test was used [41]. Next, to examine the association between screen time and the five developmental health outcomes, five logistic regression models with generalizing estimating equations (GEE) were built ('xtlogit' command with 'population average' option in STATA). The GEE was used as estimators of variance, employing an exchangeable correlation structure to account for clustering in the data (i.e., children nested within schools) [42, 43]. School ID was used as a cluster variable. The school-level variability on developmental health outcomes ranged from ICC $=0.12$ to $\mathrm{ICC}=0.14$.

Of 2,983 children in the linked sample, $853(28.6 \%)$ had missing values on one or more variables; 165 (5.53\%) had missing information on at least one developmental health domain (see Table 1). Based on bivariate analyses with missing indicator variable, information was presumed to be 'missing at random' (MAR) and multiple imputation (MI) using chained equation approach was used to impute missing values [44]. The process was repeated $m=28$ times $[45,46]$. At the final stage, following Rubin's rules, [47] parameter estimates were pooled. Imputed values for outcome variables were excluded post imputation under 'multiple imputation then deletion' (MID) approach [48]. As a result, 2818 (94.5\%) children with complete information on outcome variables were included in the GEE analyses.

In building the multivariable models, all the covariates were entered simultaneously into the model based on their role as potential confounder and bivariate association with the outcome [17, 26-29]. Unadjusted and adjusted odds ratios (ORs) and corresponding 95\% confidence interval (CIs) were reported for each developmental health outcome. A two-way interaction between screen time and income was explored using analysis of variance (ANOVA). To support the stability of the findings, sensitivity analyses were conducted, using linear regression models predicting scores on the five developmental outcomes in their continuous, non-dichotomized form. A sensitivity analysis was also performed on the 
sub-sample of children with complete data before the imputation of missing values $(N=2130)$ to examine whether results were comparable. All analyses were completed using STATA version 16 [49].

\section{Results}

Family income was negatively related to screen time $\left(\mathrm{x}^{2}=25.8, \mathrm{df}=1, p<0.001\right)$; children in families with lower annual household income (i.e., $<\$ 75,000$ ) were significantly more likely to have high levels of screen time compared to children in higher income families (i.e., $\geq \$ 75,000$ ). Specifically, among children from lower income families, $46.6 \% \mathrm{had}>1 \mathrm{~h}$ of screen time per day, whereas $53.4 \%$ had $\leq 1 \mathrm{~h}$ of screen time per day; among children from higher income families, $35.7 \%$ had $>1 \mathrm{~h}$ of screen time per day and $64.2 \%$ had $\leq 1 \mathrm{~h}$ of screen time per day. Table 2 shows the results of bivariate analyses on the association between explanatory variables on the CHEQ and dependent variables on the EDI.

The results of bivariate analyses suggest that children with screen time of $>1 \mathrm{~h}$ per day were more likely than children with $\leq 1 \mathrm{~h}$ per day to be developmentally vulnerable on all domains of developmental health. Furthermore, boys were more likely to be vulnerable than girls; children living in families of non-European origins were more likely to be vulnerable than those of European origins; children living in families with annual family income $<75,000$ were more likely to be vulnerable than children in families with annual family income $\geq 75,000$; children who did not participate in structured physical

Table 2 Bivariate Relationships Between Explanatory Variables and Vulnerability (Vulnerable vs. Not Vulnerable) on Five Developmental Health Domains Among Preschool-Aged Children in British Columbia, Canada, using Logistic Regression Model Reporting Crude Odds Ratios And 95\% Confidence Intervals

\begin{tabular}{|c|c|c|c|c|c|}
\hline & $\begin{array}{l}\text { Physical } \\
\text { health and wellbeing }\end{array}$ & $\begin{array}{l}\text { Social } \\
\text { competence }\end{array}$ & Emotional maturity & $\begin{array}{l}\text { Language } \\
\text { and cognitive } \\
\text { development }\end{array}$ & Communication skills \\
\hline & $\begin{array}{l}\text { OR } \\
(95 \% \mathrm{Cl})\end{array}$ & $\begin{array}{l}\text { OR } \\
(95 \% \mathrm{Cl})\end{array}$ & $\begin{array}{l}\text { OR } \\
(95 \% \mathrm{Cl})\end{array}$ & $\begin{array}{l}\text { OR } \\
(95 \% \mathrm{Cl})\end{array}$ & $\begin{array}{l}\text { OR } \\
(95 \% \mathrm{Cl})\end{array}$ \\
\hline \multicolumn{6}{|l|}{ Screen time } \\
\hline$>1 \mathrm{~h}$ & $\begin{array}{l}1.86^{* * *} \\
(1.46-2.37)\end{array}$ & $\begin{array}{l}1.78^{* * *} \\
(1.43-2.23)\end{array}$ & $\begin{array}{l}1.62^{* * *} \\
(1.31-1.99)\end{array}$ & $\begin{array}{l}1.93^{* * *} \\
(1.47-2.52)\end{array}$ & $\begin{array}{l}1.74^{* * *} \\
(1.35-2.23)\end{array}$ \\
\hline$\leq 1 \mathrm{~h}$ & Reference & & & & \\
\hline \multicolumn{6}{|l|}{ Sex } \\
\hline Male & $\begin{array}{l}1.8^{* * *} \\
(1.4-2.3)\end{array}$ & $\begin{array}{l}2.85^{* * *} \\
(2.24-3.63)\end{array}$ & $\begin{array}{l}3.13^{* * *} \\
(2.48-3.95)\end{array}$ & $\begin{array}{l}1.4^{*} \\
(1.07-1.83)\end{array}$ & $\begin{array}{l}1.93^{* * *} \\
(1.49-2.5)\end{array}$ \\
\hline Female & Reference & & & & \\
\hline \multicolumn{6}{|l|}{ Ethnicity } \\
\hline European origins & $\begin{array}{l}0.91 \\
(0.7-1.18)\end{array}$ & $\begin{array}{l}0.75^{*} \\
(0.59-0.94)\end{array}$ & $\begin{array}{l}0.11 \\
(1.16-1.16)\end{array}$ & $\begin{array}{l}0.61^{* *} \\
(0.45-0.82)\end{array}$ & $\begin{array}{l}0.4^{* * *} \\
(0.3-0.53)\end{array}$ \\
\hline Not Euro. origins & Reference & & & & \\
\hline \multicolumn{6}{|c|}{ Annual household income } \\
\hline$<\$ 75,000$ & $\begin{array}{l}2.2^{* * *} \\
(1.68-2.89)\end{array}$ & $\begin{array}{l}2.06^{* * *} \\
(1.61-2.64)\end{array}$ & $\begin{array}{l}1.77^{* * *} \\
(1.41-2.23)\end{array}$ & $\begin{array}{l}2.81^{* * *} \\
(2.09-3.76)\end{array}$ & $\begin{array}{l}2.26^{* * *} \\
(1.66-3.08)\end{array}$ \\
\hline$\geq \$ 75,000$ & Reference & & & & \\
\hline \multicolumn{6}{|l|}{ Population Centre } \\
\hline Urban & $\begin{array}{l}0.84 \\
(0.63-1.12)\end{array}$ & $\begin{array}{l}1.01 \\
(0.76-1.35)\end{array}$ & $\begin{array}{l}0.84 \\
(0.63-1.11)\end{array}$ & $\begin{array}{l}0.81 \\
(0.6-1.08)\end{array}$ & $\begin{array}{l}1.43^{*} \\
(1.07-1.9)\end{array}$ \\
\hline Small to medium & Reference & & & & \\
\hline \multicolumn{6}{|l|}{ Physical activity } \\
\hline Nonparticipant & $\begin{array}{l}2.79^{* * *} \\
(2.14-3.65)\end{array}$ & $\begin{array}{l}2.14^{* * *} \\
(1.66-2.75)\end{array}$ & $\begin{array}{l}1.88^{* * *} \\
(1.47-2.41)\end{array}$ & $\begin{array}{l}2.73^{* * *} \\
(2.03-3.65)\end{array}$ & $\begin{array}{l}2.65^{* * *} \\
(2.01-3.5)\end{array}$ \\
\hline Participant & Reference & & & & \\
\hline \multicolumn{6}{|l|}{ Sleep } \\
\hline$<10 h$ & $\begin{array}{l}1.68^{* *} \\
(1.19-2.38)\end{array}$ & $\begin{array}{l}1.79^{* * *} \\
(1.31-2.46)\end{array}$ & $\begin{array}{l}1.88^{* * *} \\
(1.39-2.53)\end{array}$ & $\begin{array}{l}2.21^{* * *} \\
(1.54-3.16)\end{array}$ & $\begin{array}{l}2.12^{* * *} \\
(1.51-2.97)\end{array}$ \\
\hline$\geq 10 \mathrm{~h}$ & Reference & & & & \\
\hline
\end{tabular}


activity were more likely to be vulnerable compared to participants; children with $<10 \mathrm{~h}$ of sleep were more likely to be vulnerable compared to children with $\geq 10 \mathrm{~h}$ of sleep on all developmental domains.

Results of multivariable analyses for the association between screen time and developmental health among children are reported in Table 3. The adjusted odds ratio (OR) represents the average odds of being vulnerable on a developmental domain for the preschool children in our study with screen time of $>1 \mathrm{~h}$ per day compared to those having screen time of $\leq 1 \mathrm{~h}$ per day. Accordingly, children with screen time of $>1 \mathrm{~h}$ per day compared to screen time of $\leq 1 \mathrm{~h}$ in a day were $41 \%$ more likely to be vulnerable regarding their physical health and wellbeing $(O R=1.41 ; 95 \%$ CI $0.99-2.0 ; p=0.058), 60 \%$ more likely to be vulnerable regarding their social competence (OR $=1.60 ; 95 \%$ CI $1.16-2.2 ; p=0.004$ ), $29 \%$ more likely to be vulnerable regarding their emotional maturity (OR $=1.29 ; 95 \%$ CI $0.96-1.73 ; p=0.097), 81 \%$ more likely to be vulnerable regarding their language and cognitive development $(O R=1.81 ; 95 \%$ CI $1.19-2.74 ; p=0.006)$ and $60 \%$ more likely to be vulnerable regarding their

Table 3 Multivariable Logistic Regression Model Reporting Adjusted Odds Ratios And 95\% Confidence Intervals for Relationship Between Screen Time and Vulnerability (Vulnerable vs. Not Vulnerable) on Five Developmental Health Domains Among PreschoolAged Children in British Columbia, Canada

\begin{tabular}{|c|c|c|c|c|c|}
\hline & $\begin{array}{l}\text { Physical } \\
\text { health and wellbeing }\end{array}$ & $\begin{array}{l}\text { Social } \\
\text { competence }\end{array}$ & Emotional maturity & $\begin{array}{l}\text { Language } \\
\text { and cognitive } \\
\text { development }\end{array}$ & Communication skills \\
\hline & $\begin{array}{l}\text { OR } \\
(95 \% \mathrm{Cl})\end{array}$ & $\begin{array}{l}\text { OR } \\
(95 \% \mathrm{Cl})\end{array}$ & $\begin{array}{l}\text { OR } \\
(95 \% \mathrm{Cl})\end{array}$ & $\begin{array}{l}\text { OR } \\
(95 \% \mathrm{Cl})\end{array}$ & $\begin{array}{l}\text { OR } \\
(95 \% \mathrm{Cl})\end{array}$ \\
\hline \multicolumn{6}{|l|}{ Screen time } \\
\hline$>1 \mathrm{~h}$ & $\begin{array}{l}1.41^{\dagger 1} \\
(0.99-2)\end{array}$ & $\begin{array}{l}1.60^{* *} \\
(1.16-2.2)\end{array}$ & $\begin{array}{l}1.29^{+2} \\
(0.96-1.73)\end{array}$ & $\begin{array}{l}1.81^{* *} \\
(1.19-2.74)\end{array}$ & $\begin{array}{l}1.60^{*} \\
(1.1-2.34)\end{array}$ \\
\hline$\leq 1 \mathrm{~h}$ & Reference & & & & \\
\hline \multicolumn{6}{|l|}{ Sex } \\
\hline Male & $\begin{array}{l}1.73^{* * *} \\
(1.34-2.23)\end{array}$ & $\begin{array}{l}2.83^{* * *} \\
(2.21-3.63)\end{array}$ & $\begin{array}{l}3.13^{* * *} \\
(2.47-3.96)\end{array}$ & $\begin{array}{l}1.36^{*} \\
(1.03-1.79)\end{array}$ & $\begin{array}{l}1.95^{* * *} \\
(1.49-2.55)\end{array}$ \\
\hline Female & Reference & & & & \\
\hline \multicolumn{6}{|l|}{ Ethnicity } \\
\hline European origins & $\begin{array}{l}1.12 \\
(0.84-1.49)\end{array}$ & $\begin{array}{l}0.88 \\
(0.68-1.13)\end{array}$ & $\begin{array}{l}1.08 \\
(0.84-1.38)\end{array}$ & $\begin{array}{l}0.77 \\
(0.56-1.06)\end{array}$ & $\begin{array}{l}0.49^{* * *} \\
(0.36-0.66)\end{array}$ \\
\hline Not Euro. origins & Reference & & & & \\
\hline \multicolumn{6}{|l|}{ Annual household income } \\
\hline$<\$ 75,000$ & $\begin{array}{l}1.55^{*} \\
(1.03-2.31)\end{array}$ & $\begin{array}{l}1.89^{* *} \\
(1.32-2.7)\end{array}$ & $\begin{array}{l}1.42^{*} \\
(1.02-1.98)\end{array}$ & $\begin{array}{l}2.42^{* * *} \\
(1.56-3.77)\end{array}$ & $\begin{array}{l}1.98^{* *} \\
(1.27-3.1)\end{array}$ \\
\hline$\geq \$ 75,000$ & Reference & & & & \\
\hline \multicolumn{6}{|l|}{ Population Centre } \\
\hline Urban & $\begin{array}{l}0.92 \\
(0.67-1.27)\end{array}$ & $\begin{array}{l}1.02 \\
(0.77-1.36)\end{array}$ & $\begin{array}{l}0.86 \\
(0.66-1.14)\end{array}$ & $\begin{array}{l}0.83 \\
(0.62-1.11)\end{array}$ & $\begin{array}{l}1.42^{*} \\
(1.07-1.88)\end{array}$ \\
\hline Small to medium & Reference & & & & \\
\hline \multicolumn{6}{|l|}{ Physical activity } \\
\hline Nonparticipant & $\begin{array}{l}2.2^{* * *} \\
(1.66-2.92)\end{array}$ & $\begin{array}{l}1.68^{* * *} \\
(1.28-2.2)\end{array}$ & $\begin{array}{l}1.52^{* *} \\
(1.17-1.99)\end{array}$ & $\begin{array}{l}1.99^{* * *} \\
(1.46-2.7)\end{array}$ & $\begin{array}{l}2.12^{* * *} \\
(1.57-2.87)\end{array}$ \\
\hline Participant & Reference & & & & \\
\hline \multicolumn{6}{|l|}{ Sleep } \\
\hline$<10 \mathrm{~h}$ & $\begin{array}{l}1.43^{\dagger} \\
(0.99-2.05)\end{array}$ & $\begin{array}{l}1.51^{*} \\
(1.08-2.12)\end{array}$ & $\begin{array}{l}1.71^{* *} \\
(1.25-2.36)\end{array}$ & $\begin{array}{l}1.69^{* *} \\
(1.15-2.48)\end{array}$ & $\begin{array}{l}1.63^{* *} \\
(1.14-2.33)\end{array}$ \\
\hline$\geq 10 \mathrm{~h}$ & Reference & & & & \\
\hline Screen time $X$ Income & $\begin{array}{l}1.31 \\
(0.78-2.19)\end{array}$ & $\begin{array}{l}0.87 \\
(0.53-1.4)\end{array}$ & $\begin{array}{l}1.21 \\
(0.76-1.95)\end{array}$ & $\begin{array}{l}0.77 \\
(0.43-1.38)\end{array}$ & $\begin{array}{l}0.72 \\
(0.4-1.28)\end{array}$ \\
\hline
\end{tabular}

Notes. $N=2,818 .{ }^{* * *} p<0.001 .{ }^{* *} p<0.01 .{ }^{*} p<0.05$. For each of the five developmental health domains, vulnerable is coded as 1 and not vulnerable is coded as 0 .

${ }^{+}$indicates marginal significance at $p<0.109$

${ }^{1}$ When the interaction term is removed from the model, OR $\left.1.58 ; 95 \% \mathrm{Cl} 1.23-2.04\right) ; p<0.001$

${ }^{2}$ When the interaction term is removed from the model, OR $1.39 ; 95 \% \mathrm{Cl} 1.12-1.73$ ); $p<0.01$ 
communication skills $(O R=1.60 ; 95 \%$ CI $1.1-2.34 ; p$ $=0.015$ ). Estimates were adjusted for child sex, family income, ethnicity, rural/urban community living, sleep, and physical activity. There was no significant interaction between income and screen time in relation to any of the developmental outcomes. Note that when removing the non-significant interaction term from the models, the marginally significant effects of screen time on physical health and wellbeing, and on emotional maturity changed to statistical significance (physical health and wellbeing: $O R=1.58$; 95\% CI $1.23-2.04$ ); $p<0.001$; emotional maturity: $O R=1.39 ; 95 \%$ CI $1.12-1.73) ; p=$ 0.003 .

Sensitivity analyses based on the sub-sample of children with complete data supported the stability of our findings (see Table S1). Similarly, sensitivity analyses using linear regression models showed that the direction and statistical significance of all results were consistent with those obtained from logistic regression analyses (see Table S2).

\section{Discussion}

Our findings show that screen use that exceeds the recommended daily amount in the early years is associated with developmental vulnerability. Specifically, more than one hour of screen time per day was positively associated with vulnerability in physical, social, emotional, and cognitive developmental health domains. These associations were statistically significant over and above children's further health behaviors - physical activity and sleep, as well as income and other demographics. Our results substantiate the findings from previous research that have shown a negative link between screen time and physical [50], social-emotional [51] and mental health [7] outcomes among preschool-aged children. They further extend past research on screen time and early child development by taking a whole-child approach that incorporates multiple domains of developmental health (i.e., physical, social, emotional, cognitive), while also taking into account multiple health behaviors and child/family demographics.

In the present study, $39.7 \%$ of children engaged in screen time for more than one hour per day. Evidence indicates that screen use appears to be increasing for Canadian children under five [2]. High levels of screen time were more common in males, children with nonEuropean ethnic backgrounds, and children with family income below $\$ 75,000$ in our study. These findings are in line with previous research [52] and point to social disparities in screen time. This is an important finding because recent research with young children in several European countries has found that children experiencing socio-economic vulnerability - including low family income - spent more time in screen-based activities [53].
Several explanations have been offered for why children from lower income families tend to have more screen time. For example, for parents in lower SES families child care is difficult to afford and they often have other competing demands (e.g., work, other caregiving responsibilities) while taking care of younger children [13, 54]. In contrast to a previous study (13), family income did not moderate the relationship between screen time and developmental outcomes in our study.

High levels of screen time during the early years can be potentially detrimental for achieving developmental milestones, especially school readiness. While causality cannot be implied in this study, longer screen time can interfere with positive and health-promoting experiences such as physical activity, social contact with peers and family, and good sleep hygiene [12]. Moreover, high levels of screen time are of concern for developmental health because it tends to displace free play-based and leisure activities that enhance cognitive and social-emotional skills that are key in promoting Kindergarten readiness $[11,55]$. More research is needed to examine the underlying mechanisms and pathways through which screen time is linked to developmental vulnerabilities.

\section{Limitations}

Since schools' and parents' participation in the study was voluntary, non-response bias from the schools that didn't participate in the survey and parents who didn't participate in the data collection have to be considered. Particularly, children whose parents did not complete the CHEQ survey were more vulnerable on the EDI domains than children on whose parents participated in the CHEQ (see Table S3). Previous research has shown that selection bias in such case leads to an underestimation of the association between the risk factor (i.e., high screen time) and outcome (i.e., vulnerability on EDI domains) [56]. Further, the CHEQ survey was only available in English and parents who were unable to read/understand English may not have participated. Hence, findings from this study may not be generalizable to other sub-populations of children in $\mathrm{BC}$ or Canada.

Limitations to the health behavior measures used in this study have to be noted. A common challenge with measuring screen time and other health behaviors is the subjectivity and potential recall bias of self-report measures provided by parents. Also, due to social desirability, some parents may under-report undesirable behaviors of their children. Lastly, even though the data on the CHEQ were collected six months prior to the EDI survey, temporality and causality cannot be established. It is possible that other underlying factors that were not measured contributed to both screen time and developmental health in this study. 
An area of future research is to disentangle the specific contents of screen time and type of screen-based activities children in relation to developmental health. More studies are required to understand mechanisms, examine quality and content of screen use beyond quantity, and track children's development and health longitudinally over time to provide more insight on supporting more specific policy recommendations for age appropriate screen use.

\section{Conclusions}

Early experiences and behaviors play a crucial role in shaping a child's developmental trajectories. Our study, drawing from a large-scale early childhood study, shows a negative association between longer screen time and young children's developmental health in five core domains: physical, social, emotional, and cognitive development. These findings underscore the importance of limiting screen time in early childhood - as suggested by the 24-hour guidelines - and call for action to support the implementation of these guidelines in the Canadian context.

\begin{abstract}
Abbreviations
STROBE: Strengtheningthe Reporting of Observational Studies in Epidemiology; BC: BritishColumbia; CHEQ: ChildhoodExperiences Questionnaire; EDI: EarlyDevelopment Instrument; SD: StandardDeviation; GEE: GeneralizedEstimating Equations; OR: OddsRatio; ANOVA: Analysisof Variance; MCAR: Missingcompletely at Random; MAR: Missingat random; MID: Multipleimputation then deletion; ICC: IntraclassCorrelation.
\end{abstract}

\section{Supplementary Information}

The online version contains supplementary material available at https://doi. org/10.1186/s12889-022-12701-3.

\section{Additional file 1.}

\section{Acknowledgements}

We would like to thank all families and educators for their participation in this research.

\begin{abstract}
Authors' contributions
SK developed research questions, designed a data analytic plan, analyzed data, interpreted results, and wrote the manuscript. EO contributed to the development of research questions, analytic plan, interpretation of results, and writing of the manuscript. AA contributed to the development of the CHEQ survey, provided critical input to earlier drafts of this manuscript. MG contributed to the development of CHEQ and the EDI and provided critical input to earlier drafts of this manuscript. BF contributed to the development of CHEQ and the $\mathrm{EDI}$ and provided critical input to earlier drafts of this manuscript. All authors read and approved the final manuscript.
\end{abstract}

\section{Funding}

SK received funding from the Cordula and Gunter Paetzold Fellowship (University of British Columbia, Canada) and the Society to Cell Clyde Hertzman Memorial Fellowship (Social Exposome Cluster and the Human Early Learning Partnership, University of British Columbia, Canada); EO received funding from the Social Sciences and Humanities Research Council of Canada.

\section{Availability of data and materials}

Data supporting the findings of this study are not publicly available for ethical and privacy reasons because the data pertain to individuals. In alignment with regulations for accessing population-level data in Canada, data can be accessed through Population Data BC's Secure Research Environment cloud server and can be made available upon request and permission from the data steward through dataaccess@popdata.bc.ca.

\section{Declarations}

\section{Ethics approval and consent to participate}

Ethics approval for this study was obtained from the Behavioural Research Ethics Board, University of British Columbia, Canada (H1901043). All methods were performed in accordance with the Declaration of Helsinki. Parents/ caregivers provided informed consent for completing the CHEQ survey while informed passive consent was obtained from parents/guardians before implementing the EDI survey approved by the Behavioural Research Ethics Board, University of British Columbia, Canada.

\section{Consent for publication \\ Not applicable.}

\section{Competing interests}

The authors declare that they have no competing interests.

Received: 5 May 2021 Accepted: 28 January 2022

Published online: 15 February 2022

\section{References}

1. Chen W, Adler JL. Assessment of Screen Exposure in Young Children, 1997 to 2014. JAMA Pediatrics. 2019;173:391.

2. Madigan S, Racine N, Tough S. Prevalence of Preschoolers Meeting vs Exceeding Screen Time Guidelines. JAMA Pediatrics. 2020;174:93.

3. Kabali HK, Irigoyen MM, Nunez-Davis R, Budacki JG, Mohanty SH, Leister $\mathrm{KP}$, et al. Exposure and use of mobile media devices by young children. Pediatrics. 2015;136:1044-50.

4. Radesky JS, Schumacher J, Zuckerman B. Mobile and interactive media use by young children: The good, the bad, and the unknown. Pediatrics. 2015;135:1-3.

5. Fang K, Mu M, Liu K, He Y. Screen time and childhood overweight/obesity: A systematic review and meta-analysis. Child 2019;45:744-53.

6. Tamana SK, Ezeugwu V, Chikuma J, Lefebvre DL, Azad MB, Moraes TJ, et al. Screen-time is associated with inattention problems in preschoolers: Results from the CHILD birth cohort study. PLOS ONE. 2019;14:e0213995.

7. Del Pozo-Cruz B, Perales F, Parker P, Lonsdale C, Noetel M, Hesketh KD, et al. Joint physical-activity/screen-time trajectories during early childhood: Socio-demographic predictors and consequences on healthrelated quality-of-life and socio-emotional outcomes. International Journal of Behavioral Nutrition and Physical Activity. 2019;16:55.

8. van den Heuvel M, Ma J, Borkhoff CM, Koroshegyi C, Dai DWH, Parkin PC, et al. Mobile Media Device Use is Associated with Expressive Language Delay in 18-Month-Old Children. Journal of Developmental \& Behavioral Pediatrics. 2019;40:99-104.

9. Kostyrka-Allchorne K, Cooper NR, Simpson A. The relationship between television exposure and children's cognition and behaviour: A systematic review. Developmental Review. 2017:44:19-58.

10. Adelantado-Renau M, Moliner-Urdiales D, Cavero-Redondo I, Beltran-Valls MR, Martínez-Vizcaíno V, Álvarez-Bueno C. Association Between Screen Media Use and Academic Performance Among Children and Adolescents. JAMA Pediatrics. 2019;173:1058.

11. Sigman A. Screen Dependency Disorders: a new challenge for child neurology. J Int Child Neurol Assoc. 2017;1.

12. Sigman A. Time for a view on screen time. Archives of Disease in Childhood. 2012;97:935-42.

13. Ribner A, Fitzpatrick C, Blair C. Family Socioeconomic Status Moderates Associations between Television Viewing and School Readiness Skills. J Develop Behav Pediatrics. 2017;38:233-9. 
14. Tremblay MS, Chaput JP, Adamo KB, Aubert S, Barnes JD, Choquette L, et al. Canadian 24-Hour Movement Guidelines for the Early Years (0-4 years): An Integration of Physical Activity, Sedentary Behaviour, and Sleep. BMC Public Health. 2017;17:874.

15. Tremblay MS. Introducing 24-Hour Movement Guidelines for the Early Years: A New Paradigm Gaining Momentum. J Physical Activity Health. 2020;17:92-5

16. Chaput JP, Colley RC, Aubert S, Carson V, Janssen I, Roberts KC, et al. Proportion of preschool-aged children meeting the Canadian 24-Hour Movement Guidelines and associations with adiposity: Results from the Canadian Health Measures Survey. BMC Public Health. 2017;17 Suppl 5.

17. Stiglic N, Viner RM. Effects of screentime on the health and well-being of children and adolescents: A systematic review of reviews. BMJ Open. 2019:9:23191.

18. Hancox RJ, Milne BJ, Poulton R. Association between child and adolescent television viewing and adult health: a longitudinal birth cohort study. Lancet. 2004;364:257-62.

19. Twenge JM, Campbell WK. Associations between screen time and lower psychological well-being among children and adolescents: Evidence from a population-based study. Preventive Medicine Reports. 2018;12:271-83.

20. von Elm E, Altman DG, Egger M, Pocock SJ, Gøtzsche PC, Vandenbroucke JP. The Strengthening the Reporting of Observational Studies in Epidemiology (STROBE) statement: guidelines for reporting observational studies. J Clin Epidemiol. 2008:61:344-9.

21. The Human Early Learning Partnership. The Childhood Experiences Questionnaire. University of British Columbia. 2021. http://earlylearning. ubc.ca/cheq/. Accessed 27 Jan 2021

22. The Human Early Learning Partnership. The Early Development Instrument. University of British Columbia. 2021. http://earlylearning.ubc.ca/ edi/. Accessed 27 Jan 2021.

23. Parent N, Guhn M, Brussoni M, Almas A, Oberle E. Social determinants of playing outdoors in the neighbourhood: family characteristics, trust in neighbours and daily outdoor play in early childhood. Can J Public Health. 2021:112:120-7.

24. Population Data BC. The data linkage process. The University of British Columbia. 2021. https://www.popdata.bc.ca/datalinkage/process. Accessed 27 Jan 2021

25. Population Data BC. Data sets available. The University of British Columbia. 2020. https://www.popdata.bc.ca/data. Accessed 27 Jan 2021.

26. Madigan S, Browne D, Racine N, Mori C, Tough S. Association between Screen Time and Children's Performance on a Developmental Screening Test. JAMA Pediatrics. 2019;173:244-50.

27. Duch H, Fisher EM, Ensari I, Harrington A. Screen time use in children under 3 years old: A systematic review of correlates. Int J Behav Nutri Physical Activity. 2013;10:102.

28. Hoyos Cillero I, Jago R. Systematic review of correlates of screen-viewing among young children. Preventive Medicine. 2010;51:3-10.

29. Janus M, Duku E. The School Entry Gap: Socioeconomic, Family, and Health Factors Associated With Children's School Readiness to Learn. Early Educ Dev. 2007:18:375-403.

30. Chen C, Sellberg F, Ahlqvist VH, Neovius M, Christiansen F, Berglind D. Associations of participation in organized sports and physical activity in preschool children: a cross-sectional study. BMC Pediatrics. 2020;20:328.

31. First Call: BC Child and Youth Advocacy Coalition. Living Wages in BC and Canada - Living Wage for Families Campaign. The Living Wage for Families Campaign. 2014. http://www.livingwageforfamilies.ca/living_wage_ rates. Accessed 14 Aug 2020.

32. Statistics Canada. Population Centre and Rural Area Classification 2016. Government of Canada, Statistics Canada. 2017. https://www.statcan.gc ca/eng/subjects/standard/pcrac/2016/introduction. Accessed 14 Aug 2020

33. Guhn M, Gadermann AM, Hertzman C, Zumbo BD. Children's Development in Kindergarten: A Multilevel, Population-Based Analysis of ESL and Gender Effects on Socioeconomic Gradients. Child Indicators Research. 2010;3:183-203.

34. Davies S, Janus M, Duku E, Gaskin A. Using the Early Development Instrument to examine cognitive and non-cognitive school readiness and elementary student achievement. Early Childhood Research Quarterly. 2016:35:63-75.
35. The Human Early Learning Partnership. Vulnerability on the EDI [Fact sheet]. 2013.

36. D'Angiulli A, Warburton W, Dahinten S, Hertzman C. Population-Level Associations between Preschool Vulnerability and Grade-Four Basic Skills. PLoS ONE. 2009:4:e7692.

37. Razaz N, Boyce WT, Brownell M, Jutte D, Tremlett H, Marrie RA, et al. Five-minute Apgar score as a marker for developmental vulnerability at 5 years of age. Arch Dis Childhood - Fetal Neonatal Edition. 2016:101:F114-20.

38. Janus M, Offord DR. Development and psychometric properties of the Early Development Instrument (EDI): A measure of children's schoo readiness. Can J Behav Sci. 2007;39:1-22.

39. Forer B, Zumbo BD. Validation of Multilevel Constructs: Validation Methods and Empirical Findings for the EDI. Soc Indicators Res. 2011;103:231-65.

40. Hymel S, LeMare L, McKee W. The Early Development Instrument: An Examination of Convergent and Discriminant Validity. Soc Indicators Res. 2011:103:267-82

41. Rao JNK, Scott. AJ. On Simple Adjustments to Chi-Square Tests with Sample Survey Data. The Annals of Statistics. 1987:15:385-97.

42. Hanley JA. Statistical Analysis of Correlated Data Using Generalized Estimating Equations: An Orientation. American Journal of Epidemiology. 2003;157:364-75

43. Cui J, Qian G. Selection of working correlation structure and best model in GEE analyses of longitudinal data. Commun Stat Simulation Computation. 2007;36:987-96.

44. van Buuren S, Groothuis-Oudshoorn K. mice: Multivariate Imputation by Chained Equations in R. J Stat Software. 2011;45:1-67.

45. White IR, Royston P, Wood AM. Multiple imputation using chained equations: Issues and guidance for practice. Stat Med. 2011;30:377-99.

46. Graham JW, Olchowski AE, Gilreath TD. How Many Imputations are Really Needed? Some Practical Clarifications of Multiple Imputation Theory. Prevention Science. 2007:8:206-13.

47. Rubin DB. Multiple Imputation for Nonresponse in Surveys. Volume 81. Hoboken, New Jersey: John Wiley \& Sons; 2004.

48. Von Hippel PT. 4. Regression with Missing Ys: An Improved Strategy for Analyzing Multiply Imputed Data. Sociological Methodology. 2007:37:83-117.

49. StataCorp. Stata Statistical Software: Release 16. 2019

50. Kim H, Ma J, Harada K, Lee S, Gu Y. Associations between Adherence to Combinations of 24-h Movement Guidelines and Overweight and Obesity in Japanese Preschool Children. Int J Environ Res Public Health. 2020;17:9320.

51. Hinkley T, Brown H, Carson V, Teychenne M. Cross sectional associations of screen time and outdoor play with social skills in preschool children. PLOS ONE. 2018;13:e0193700.

52. Przybylski AK, Weinstein N. Digital Screen Time Limits and Young Children's Psychological Well-Being: Evidence From a Population-Based Study. Child Development. 2019:90:e56-65.

53. Iguacel I, Fernández-Alvira JM, Bammann K, Chadjigeorgiou C, De Henauw S, Heidinger-Felső R, et al. Social vulnerability as a predictor of physical activity and screen time in European children. Int J Public Health. 2018:63:283-95.

54. Määttä S, Kaukonen R, Vepsäläinen $H$, Lehto E, Ylönen A, Ray C, et al. The mediating role of the home environment in relation to parental educational level and preschool children's screen time: a cross-sectional study. BMC Public Health. 2017;17:688

55. Pagani LS, Fitzpatrick C, Barnett TA, Dubow E. Prospective associations between early childhood television exposure and academic, psychosocial, and physical well-being by middle childhood. Arch Pediatrics Adolescent Med. 2010;164:425-31.

56. Wolke D, Waylen A, Samara M, Steer C, Goodman R, Ford T, et al. Selective drop-out in longitudinal studies and non-biased prediction of behaviour disorders. Brit J Psychiatry. 2009;195:249-56.

\section{Publisher's Note}

Springer Nature remains neutral with regard to jurisdictional claims in published maps and institutional affiliations. 